\title{
A formação profissional dos assistentes sociais em tempos de contrarreformas do ensino superior: o impacto das mais recentes propostas do governo Lula
}

\author{
The social workers' professional background in times of \\ counter-reformation in upper education: the impact of the latest \\ proposals by president Lula's government
}

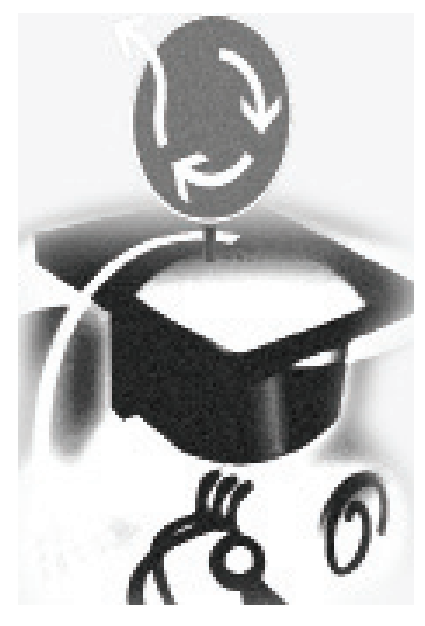

Juliana Fiuza Cislaghi*

Resumo: Desde 1990, as universidades brasileiras vêm passando por uma contrarreforma que visa adequá-las às necessidades do capitalismo atual. Essa realidade mais recentemente tem afetado as universidades públicas por meio de mudanças curriculares, superexploração do trabalho docente e financiamento por contratos de gestão, o que impacta negativamente a formação dos assistentes sociais, da forma como é preconizada pelo projeto ético-político profissional.

Palavras-chave: Formação profissional. Serviço Social. Contrarreforma universitária. Programa Reuni.

\begin{abstract}
The Brazilian universities have been counter-reformed since 1990 in order to adjust to the needs of contemporary capitalism. Recently, this reality has affected the public universities through curricular changes, professors' overexploitation and funding by management contracts, which impacts into the social workers' background negatively, regarding the recommendations of the ethical-political project.
\end{abstract}

Keywords: Professional background. Social Services. Counter-reformation in upper education. Reuni program.

* Assistente social, mestre em Serviço Social pela UERJ — Rio de Janeiro/RJ, professora assistente da Faculdade de Serviço Social da UERJ — Rio de Janeiro, Brasil.E-mail: fiuzajuliana@yahoo.com.br. 
formação dos assistentes sociais é um dos eixos fundamentais do projeto ético-político profissional que vem sendo construído e consolidado desde a década de 1980 . Tem como um de seus marcos a elaboração de novas diretrizes curriculares, ${ }^{1}$ que buscam um perfil profissional dotado de competência teórico-crítica e técnico-política, comprometido com valores democráticos e ético-humanistas na defesa de uma "nova cidadania coletiva, capaz de abranger as dimensões econômicas, políticas e culturais da vida dos produtores de riqueza, do conjunto das classes subalternas" (Iamamoto, 2003, p. 185).

Outro importante marco na consolidação do projeto ético-político profissional foi a ampliação dos cursos de pós-graduação e da pesquisa na área. Segundo Iamamoto (2007), a investigação é central tanto na formação como na prática profissional. É a pesquisa que permite o conhecimento da realidade onde se atua, fazendo parte das funções precípuas da universidade, que não pode se limitar a ser mera transmissora de conhecimentos e formadora de força de trabalho especializada.

Mas, ainda que significativos avanços tenham sido conseguidos nesses aspectos desde a entrada do Serviço Social no âmbito universitário, as condições da universidade — políticas, infraestruturais, de financiamento etc. —, determinadas pelas políticas para o ensino superior vigentes, são fundamentais para garantir condições para afirmação desse projeto de formação. Assim, as contrarreformas no ensino superior em curso desde o governo Cardoso impactam as possibilidades de avanço em um dos espaços mais importantes de consolidação e difusão do projeto profissional dos assistentes sociais: as universidades públicas.

Se é verdade que a intensa privatização do ensino superior bem como o crescimento do ensino à distância são evidentes retrocessos na perspectiva de uma formação crítica, é necessário, sobretudo a partir das mudanças iniciadas

1. As diretrizes curriculares da Abepss - Associação Brasileira de Ensino e Pesquisa em Serviço Social (até 1998 Abess - Associação Brasileira de Ensino de Serviço Social), construídas no marco das mudanças do Serviço Social brasileiro no sentido da ruptura com o conservadorismo, foram elaboradas coletivamente e aprovadas em 1996, fundamentando um novo perfil de formação profissional consoante com a nova direção social que se consolidava como hegemônica. Ainda que bastante descaracterizadas pelo MEC quando aprovadas em 2001 como texto legal, as diretrizes desenvolvidas originalmente continuam sendo referência fundamental para o projeto ético-político profissional. 
no governo Lula, atentar para as contrarreformas em cursos a título de "reestruturação" no interior das universidades públicas.

Iamamoto afirmava que "para se pensar a construção de um novo projeto de formação profissional é decisivo enfrentar a problemática do contexto universitário" (2003, p. 195). Vários autores do Serviço Social ${ }^{2}$ vêm se debruçando sobre essa temática, mas o que observamos é que a ênfase ainda recai na ampliação do ensino privado e os limites impostos por esse quadro. Até o momento, ainda que as medidas contrarreformistas implementadas já venham trazendo inúmeras dificuldades, principalmente pela redução significativa e progressiva do financiamento, as universidades públicas são espaços que garantem relativa autonomia para a afirmação da direção social proposta pelas diretrizes construídas pela Abepss e para a realização de pesquisas críticas e comprometidas com essa direção, quadro que, acreditamos, tende a se alterar significativamente com a implementação do Reuni.

\section{Contrarreforma universitária no capitalismo tardio}

Na sua fase madura, o capitalismo mais do que nunca necessita da inovação tecnológica para aumentar a composição orgânica do capital, ampliando a produtividade e a apropriação de mais-valia relativa, acirrando a concorrência intercapitalista e, como consequência, centralizando e concentrando cada vez mais o capital. ${ }^{3}$

Nesse período novas demandas são colocadas para as universidades. A universidade clássica das duas fases anteriores do capitalismo servia, nas palavras de Mandel, para "essencialmente dar aos filhos mais inteligentes [...] da classe dirigente a educação clássica desejada e os meios de dirigir eficazmente a indústria, a nação, as colônias e o exército" (1979, p. 41). A universidade era, portanto, um instrumento de educação e meio para a coesão ideológica da classe dominante. $\mathrm{O}$ ensino profissionalizante era secundário.

2. Estamos nos referindo ao recente trabalho de Iamamoto (2007), textos de Netto que abordam a questão da formação profissional (1996), a tese de doutoramento de Dahmer Pereira (2007), além de trabalhos de assistentes sociais como a densa pesquisa de Lima (2007), que não se relaciona, porém, especificamente com a temática da formação de assistentes sociais.

3. Para um maior aprofundamento desse tema ver Mandel (1982). 
A “crise" da universidade tradicional humanista não se dá, segundo Mandel, por razões formais, isto é, excesso de estudantes, alto custo da formação, falta de infraestrutura material, nem por razões sociais globais, como um crescimento do desemprego entre a intelectualidade ou a necessidade de uso ideológico da ciência, como inclusive justificam alguns ideólogos das contrarreformas universitárias tecnocráticas. A verdadeira crise da universidade tem razões diretamente econômicas: dá-se pela necessidade de adequação de currículos, estrutura e escolha dos estudantes às necessidades de aceleração das inovações tecnológicas. No capitalismo tardio, a universidade passa por transformações, dada "a necessidade de mão de obra especializada no plano técnico na indústria e num aparelho de Estado em crescimento [...]” (Mandel, 1979, p. 42). A universidade desse período se massifica e passa a ser espaço de especialização profissional para setores da classe trabalhadora que procuram ascensão social por meio da educação superior. A terceira Revolução Industrial necessita da entrada de trabalhadores intelectuais na produção, supervisionando as máquinas e mesmo organizando o processo de trabalho. Segundo Mandel (1979, p. 43):

A aceleração da inovação tecnológica implica uma integração em larga escala do trabalho intelectual no processo de produção. Enquanto nas fases anteriores do capitalismo o trabalho intelectual estava em larga medida limitado à esfera da superestrutura social, revela-se hoje cada vez mais orientado para a infraestrutura da sociedade.

$\mathrm{O}$ autor chama esse processo de proletarização do trabalho intelectual. $\mathrm{O}$ capital passa a necessitar de produtores com capacidades específicas, tanto para a produção como para a circulação de mercadorias. A fragmentação e a alienação do trabalho penetram, assim, a esfera da ciência e da produção de conhecimento, sempre aplicado ao desenvolvimento de novos valores de uso e, mais importante, de novos valores de troca que maximizem os lucros. Mas não é só na produção que o capital vai necessitar de um novo tipo de qualificação para o trabalhador. Faz-se necessário, para adequar a reprodução da sociedade às necessidades da produção, a incorporação de força de trabalho especializada nas instituições da superestrutura.

No Brasil, assim como em outros países capitalistas periféricos, as especificidades históricas locais, bem como sua inserção no capitalismo global, fi- 
zeram com que a contrarreforma da universidade tivesse tempo e características específicas.

O processo brasileiro se assemelha ao latino-americano. Orquestradas pelas orientações do Banco Mundial e do Fundo Monetário Internacional, ${ }^{4}$ as contrarreformas universitárias voltadas para a adequação às necessidades do capitalismo tardio têm seu ápice na década de 1990. Segundo Trindade (2001, p. 29) o ensino superior teve duas fases na América Latina: uma de massificação, sobretudo entre as décadas de 1960 e 1980, hegemonicamente no setor público, e outra de privatização, já iniciada na década de 1970, mas que atinge maior fôlego na década de 1990. Até a década de 1950 apenas 2\% dos jovens entre 18 e 24 anos no continente estavam matriculados em universidades, o que demonstra a elitização do ensino nesse período. O primeiro boom na massificação se dá na década de 1960 quando esse percentual triplica, chegando a $6 \%$. Na década de 1980 chega a 13,5\%, ampliando em 1990 para 16,6\%. ${ }^{5}$ No que tange à privatização, até os anos 1970, 30\% das matrículas estavam em instituições privadas, atingindo principalmente no transcurso dos anos 1990, 45\%. Em relação ao número de instituições entre 1981 e 1995, o total de instituições privadas fundadas é quatro vezes superior ao de públicas, transformando a América Latina no maior percentual do mundo de estudantes em instituições privadas de ensino superior.

Nesse quadro já preocupante, o Brasil ainda consegue se destacar, invertendo a matrícula global. Se em 1960 tinha 40\% da matrículas no setor privado, em 1995, atingiu 65\% (Trindade, 2001, p. 30). No final do governo Cardoso, o número de matrículas privadas chega a 70\%, alcançando em 2008, durante o governo Lula a incrível taxa de $75 \%$ do total de matrículas do ensino superior! (Inep, 2009).

$\mathrm{Na}$ década de 1990, durante o governo Cardoso, a contrarreforma da universidade torna-se parte da contrarreforma do Estado que vinha sendo

4. Para se ter mais elementos sobre a relação do Banco Mundial com as contrarreformas universitárias nos países periféricos, ver Leher (1999).

5. É claro que entre os países latino-americanos, ainda que a tendência apontada seja semelhante, esse desenvolvimento é desigual. Enquanto a taxa bruta de escolarização chega na década de 1980 a $20 \%$ em países como Argentina, Venezuela e Equador, nos países com taxas mais baixas, como Colômbia, Brasil, México e Bolívia, está em patamares próximos a 10\% (Trindade, 2001, p. 27). 
implementada. Movimentos sociais ligados às universidades e à educação entram em choque com a proposta do governo em defesa da universidade pública. A proposta do governo estava em consonância com os documentos produzidos pelo Banco Mundial (1994). O objetivo declarado do Banco Mundial era orientar suas ações de apoio e financiamento nos países periféricos determinando um modelo ideal para o ensino superior a partir de experiências consideradas bem-sucedidas, em particular o modelo chileno. O diagnóstico apresentado é de que, por serem financiadas pelo orçamento do Estado, as universidades são parte das responsáveis pelas crises fiscais e mesmo assim continuam com poucos e mal aplicados recursos. Para o Banco Mundial, também é uma grande injustiça que a sociedade financie a universidade pública, quando, segundo eles, a maioria dos estudantes dessas instituições é proveniente dos setores de renda mais alta da sociedade (Druck e Figueiras, 1997). Esse discurso preparou o terreno para a contrarreforma que desde o governo Cardoso está em curso e continuou sendo aprofundada no governo Lula.

Uma proposta, incluída na LDB aprovada em 1996, prevê a diversificação das modalidades de ensino superior, na prática a flexibilização da indissociabilidade entre ensino, pesquisa e extensão, o que já estava previsto desde a Constituição de $1988 .{ }^{6}$ Isso, a princípio, favoreceu as universidades privadas, que puderam expandir cursos sequenciais e ensino à distância.

A necessidade de acelerar as inovações tecnológicas, associada a cada vez mais contundente dependência do país em relação ao capitalismo central, coloca para a universidade brasileira um novo e estratégico papel. Isso dá o tom da contrarreforma universitária nacional. Ainda que a possibilidade de ampliar a participação do capital privado no ensino superior, como um espaço gerador de lucro, seja um dos eixos norteadores da contrarreforma, suas motivações são mais profundas e estruturais. A necessidade de um novo perfil da força de trabalho formada nas universidades, de um novo perfil das pesquisas, financiadas e determinadas pelas necessidades do mercado, além da chamada racionalização de recursos públicos, para que a maior parte do fundo público se direcione ao

6. A Constituição de 1988 prevê a indissociabilidade entre ensino, pesquisa e extensão nas universidades, mas permite que o ensino superior seja organizado em outros tipos de instituições, como faculdades e centros universitários, que não precisam cumprir essa exigência. 
mercado financeiro, são parte da estratégia mundial do capital na tentativa de superar mais uma crise.

\section{Reestruturação e expansão das universidades federais: a contrarreforma do governo Lula}

Não foi apenas na política econômica que o governo Lula caracterizou-se, como Oliveira chamou, de terceiro governo da era FHC (apud Coutinho, 2003). Também em relação às universidades as medidas do governo, ainda que com inflexões e particularidades, seguiram, na sua lógica, o que vinha sendo implementado por Cardoso.

Nos anos 2000, a "reforma" do ensino superior entra numa nova fase, caracterizada pela busca de uma nova organicidade ao novo modelo que vinha sendo implementado, por meio da definição de novos parâmetros, estruturas curriculares e expansão mais acelerada do acesso a esse nível de ensino. Nos anos 2000, a meta prioritária de acesso ao ensino básico para os trabalhadores é ser ampliada, passando a incluir essa população na "educação superior de novo tipo para o século XXI" (Neves e Pronko, 2008, p. 105). É nesse segundo período que estarão localizadas as iniciativas do governo Lula.

Para esse novo período de contrarreformas, o Banco Mundial lança um novo documento em 2003 denominado "Construir sociedades de conhecimento: novos desafios para a educação terciária". Nele, o Banco afirma ampliar os temas discutidos no documento de 1994, dando ênfase a novas tendências, quais sejam: o papel emergente do conhecimento como motor do desenvolvimento, as mudanças decorrentes da ampliação do uso das tecnologias de informação e comunicação (TIC), a internacionalização tanto de provedores da educação terciária como de um mercado global de capital humano avançado, o aumento de demandas de apoio financeiro e técnico ao Banco de países que querem reformar e desenvolver a educação terciária e, por fim, a necessidade de estabelecer uma visão integrada da educação, onde a educação terciária tem papel crucial na criação de capital humano e social (Banco Mundial, 2003).

As receitas prescritas pelo Banco Mundial foram adotadas pelo Brasil com adaptações de acordo com a realidade e com os conflitos e correlações de força 
locais no embate entre o projeto neoliberal hegemônico e o projeto dos sujeitos políticos organizados ${ }^{7}$ em defesa da universidade pública. As ações determinaram uma ampliação do ensino superior privado, já hegemônico no Brasil desde o período anterior, e ao mesmo tempo mudanças que privatizaram e transformaram por dentro as universidades públicas, num processo de contrarreforma, cujo exemplo mais recente é o Programa de Apoio a Planos de Reestruturação e Expansão das Universidades Federais - Reuni -, instituído pelo Decreto n. 6.096, de 24 de abril de 2007.

O decreto caracteriza-se por um contrato de gestão que, como tal, fixa rígidas metas de desempenho para recebimento de contrapartidas financeiras. Amaral (2003, p. 118) afirma que a lógica de financiamento por contrato vinha tentando ser implementada desde o governo Cardoso. Nesse momento, os contratos de gestão estavam diretamente vinculados ao debate da transformação das Ifes em fundações públicas de direito privado ${ }^{8}$ ou organizações sociais. O governo Cardoso chega a apresentar o documento "Etapas para a viabilização da aplicação da Lei de Organizações Sociais na recriação de universidade públicas a ser administrada por contrato de gestão". Graças à rejeição da comunidade universitária, a proposta foi, por ora, deixada de lado.

O objetivo do programa, segundo o decreto, seria a criação de condições de ampliação de acesso e permanência no ensino superior "pelo melhor aproveitamento da estrutura física e de recursos humanos existentes nas universidades federais" (Brasil, 2007, grifo nosso), numa clara perspectiva racionalizadora, que parte do princípio, coincidente com o do Banco Mundial, de que há subaproveitamento nas universidades federais, diagnóstico presente no Brasil desde a reforma universitária da ditadura militar.

O programa estabelece duas metas globais que materializam esses objetivos: a elevação da taxa de conclusão média dos cursos de graduação presenciais para $90 \%$ e da relação de alunos de graduação em cursos presenciais por professor para $18 \%$, num período de cinco anos.

7. Lima (2007) destaca Andes, UNE, Ubes, Fasubra, Contee, CNTE, Anped, Anfope, Undime, Cedes e Andifes no campo contra-hegemônico, reconhecendo diferenças, entre suas pautas, avaliações e projetos.

8. "A fundação ou sociedade civil de direito privado se habilitaria a administrar os recursos humanos, as instalações e os equipamentos pertencentes ao poder público e a receber os recursos orçamentários para o seu funcionamento. Seriam celebrados contratos de gestão com o Poder Executivo para a execução de parceria entre o privado e o público" (Amaral, 2003, p. 118). 
As diretrizes do programa são: I) redução das taxas de evasão, ocupação de vagas ociosas e aumento de vagas, em particular no período noturno; II) ampliação da mobilidade estudantil, com a implantação de regimes curriculares e sistemas de títulos que possibilitem a construção de itinerários formativos, mediante o aproveitamento de créditos e a circulação de estudantes entre instituições, cursos e programas de educação superior; III) revisão da estrutura acadêmica, com a reorganização dos cursos de graduação e atualização de metodologias de ensino-aprendizagem, buscando a constante elevação da qualidade; IV) diversificação das modalidades de graduação, preferencialmente não voltadas para a profissionalização precoce e especializada; V) ampliação de políticas de inclusão e assistência estudantil; VI) articulação da graduação com a pós-graduação e da educação superior com a educação básica.

As diretrizes começam a definir, assim, sobre que bases as metas devem ser alcançadas, o que seria aprofundado no documento do MEC, "Diretrizes do Reuni", limitando os planos locais a essas orientações. Nas entrelinhas das diretrizes ficam subentendidas possibilidades de: transferência de estudantes do setor privado para o público (inciso II), ampliação do uso de EAD (inciso III) e implementação de ciclos básicos e bacharelados interdisciplinares (inciso IV), entre outras, que foram posteriormente definidas como as bolsas de docência para alunos de pós-graduação (inciso VI).

$\mathrm{Na}$ medida em que elaborassem e apresentassem seus planos as universidades teriam aportes de recursos de pessoal, custeio e investimentos. As propostas, porém, necessitariam ser aprovadas pelo MEC e os repasses estariam subordinados ao cumprimento das etapas.

Os recursos seriam destinados a: I) construção e readequação de infraestrutura e equipamentos necessários à realização dos objetivos do programa; II) compra de bens e serviços necessários ao funcionamento dos novos regimes acadêmicos; e III) despesas de custeio e pessoal associadas à expansão das atividades decorrentes do plano de reestruturação.

Em relação ao terceiro inciso, que trata dos aportes de pessoal e custeio, o decreto fixa o acréscimo a um limite de $25 \%$ das despesas de custeio e pessoal num período de cinco anos, excluindo os inativos, tendo por base o orçamento inicial da execução do plano em cada universidade, mesmo antes de definir a proporção da expansão proposta. Já no documento do MEC “Diretrizes do 
Reuni” (2007, p. 13), o acréscimo fixado é ainda menor, limitando-se a 20\% a mais no decorrer de 5 anos, tendo como parâmetro o orçamento de 2007, e a expansão exigida é de no mínimo $20 \%$ das vagas.

Com isso, o programa Reuni define uma expansão de vagas nas universidades federais, desconsiderando os déficits anteriormente acumulados nos orçamentos de custeio e pessoal. Segundo dados de Amaral (2003), só entre 1995 e 2002, os recursos de custeio, excluídos os benefícios aos trabalhadores e o pagamento de substitutos, haviam se reduzido em $62 \%$, padrão que no período posterior não foi reposto.

A expansão das vagas nas universidades públicas é uma reivindicação histórica dos sujeitos coletivos da sociedade. Desde sua origem, o Andes-SN defende a universalização do ensino superior público, compreendido como direito. Nas suas propostas para o financiamento da universidade consta: "A expansão da rede pública de ensino em todos os níveis e modalidades com recursos assegurados para o pleno aproveitamento da capacidade física instalada para ensino, pesquisa e extensão é prioridade" (Andes, 2003).

Apropriando-se dessas bandeiras, o decreto Reuni conseguiu grande adesão da sociedade. A expansão proposta, porém, está atrelada a uma reestruturação da universidade para os padrões requisitados pelo capitalismo em sua fase atual, materializados nas propostas do Banco Mundial. É, portanto, uma “jogada de mestre", que se aproveita da confiança depositada no governo Lula por sujeitos e movimentos sociais, que enxergam na expansão "nossas reivindicações", e da histórica redução dos orçamentos públicos das universidades federais, tornando os recursos prometidos pelo Reuni um sopro de esperança, após um período mais evidente de exclusivo incentivo ao ensino privado. Entretanto, não se pode perder de vista que essa suposta virada de prioridades para as instituições públicas não extinguiu o financiamento público para as instituições privadas, que, ao contrário, aumentou no governo Lula por meio do Prouni e da ampliação do Fies. ${ }^{9}$

9. Prouni é o Programa Universidade para Todos que amplia as isenções fiscais, antes exclusivas a instituições filantrópicas, a qualquer universidade privada que queira aderir ao programa, oferecendo em troca bolsas totais e parciais para estudantes de baixa renda. O Fies é um programa de financiamento estudantil onde o estudante restitui o valor das mensalidades ao governo depois de formado com juros subsidiados. Mais informações sobre esses programas podem ser encontradas em: <www.mec.gov.br>. 
Outro artigo determina que "o atendimento aos planos é condicionado à capacidade orçamentária e operacional do MEC", o que significa que não há garantias dos repasses, nem são as necessidades das universidades federais que os orientam, continuando subordinados aos limites orçamentários determinados pela política econômica e a flutuações da conjuntura.

\section{Reestruturação: as mudanças curriculares}

Segundo Lima (2009), o Reuni é uma face do projeto Universidade Nova, elaborado por docentes da UFBA. Ambos baseiam-se na mesma proposta de "nova arquitetura curricular", por meio da organização de bacharelados interdisciplinares dividindo a formação entre ciclos básicos e profissionalizantes. Porém, o projeto UniNova sofreu, críticas dos reitores por desconsiderar a necessidade de ampliação do orçamento público para garantir as metas de expansão e reestruturação, "o Reuni, portanto, é o UniNova com (algum) financiamento público" (Lima, 2009, p. 23), ainda que o decreto não faça menção explícita a suas propostas.

O projeto Universidade Nova foi lançado em 2007, quase concomitante ao Reuni, e recebido com entusiasmo pelo MEC. Ele parte do princípio de que as reformas universitárias no Brasil são incompletas porque tratam da gestão, da regulação, do financiamento, do acesso, mas não mexem nas estruturas curriculares. O diagnóstico da falência do modelo de educação superior no Brasil é dado pelos seguintes aspectos, segundo o projeto UniNova:

[...] estreitos campos do saber contemplados nos projetos pedagógicos, precocidade na escolha das carreiras, altos índices de evasão de alunos por desencanto com os estudos e por falta de condições de permanência, descompasso entre a rigidez da formação profissional e as amplas e diversificadas competências demandadas pelo mundo trabalho e, sobretudo, os desafios da Sociedade do Conhecimento, são problemas que, para sua superação, requerem modelos de formação profissional mais abrangentes, flexíveis, integradores. (UFBA, 2007b, p. 10)

Outro aspecto relevante citado no projeto é a necessidade de adequar o Brasil ao ensino superior do mundo globalizado, construindo "um modelo 
compatível tanto com o Modelo Norte-Americano, quanto com o Modelo Unificado Europeu (processo de Bolonha), sem, no entanto, significar submissão a qualquer um desses regimes" (UFBA, 2007b, p. 9).

O Processo de Bolonha teve início com um acordo assinado em 1999 por 29 ministros da Educação europeus. Seu objetivo é a criação de uma área comum europeia de ensino superior que amplie a competitividade das instituições daquele continente. As metas traçadas até o fim da primeira década de 2000 eram: ampliação da mobilidade estudantil e docente, criação de regras de equivalência de diplomas entre as instituições, divisão do ensino superior em duas fases - a primeira profissionalizante de três anos e a segunda de mestrado e doutorado (Declaração de Bolonha, 1999).

Já o modelo norte-americano é marcado pela diversificação de instituições: universidades de pesquisa, de ensino e cursos pós-secundários, os colleges, voltados para a formação rápida de mão de obra para o mercado (Ristoff, 1999).

Ainda que negue ser coincidente com os dois modelos, ${ }^{10}$ a UniNova parte do mesmo princípio de necessidade de integração e equivalência na titulação entre os países e de adequação de currículos e conteúdos às novas competências exigidas pelo mercado aos trabalhadores intelectuais. Com isso, pretende adequar a força de trabalho intelectual às necessidades do capital mundializado, ampliando as possibilidades de mobilidade da força de trabalho, o que aumenta potencialmente o exército de reserva global. Ao mesmo tempo, adequa as competências dos trabalhadores às necessidades do regime de acumulação flexível.

O Projeto Universidade Nova cita o documento que é resultado do Congresso Mundial sobre o Ensino Superior da Unesco, ocorrido em 1998, como importante fonte de dados balizadora das competências que o mercado de trabalho espera dos trabalhadores egressos do ensino superior. Essas competências

10. O Processo de Bolonha vem exatamente para disputar hegemonia com os EUA, num processo caracterizado por Lima et al. (2008) como integrador e diferenciador, ou seja, ao mesmo tempo em que cria um mercado comum europeu de educação superior para competir com outras instituições, agudiza a competição entre as instituições europeias, que aderem ao Processo de Bolonha, desconsiderando as debilidades prévias existentes. Assume, assim, "um modelo mercantil, competitivo e etnocêntrico, com claro viés imperialista". 
seriam: flexibilidade; capacidade de contribuir para a inovação, demonstrando criatividade; capacidade de enfrentar a incerteza; desejo de aprender ao longo da vida; sensibilidade social e aptidão para a comunicação; capacidade de trabalhar em equipe; espírito empreendedor; preparo para a internacionalização do mercado, familiarizando-se com culturas diferentes; largo espectro de competências genéricas em variados campos do conhecimento, especialmente das novas tecnologias, que formam a base das diversas competências profissionais. Todas são características adequadas ao princípio da polivalência e à lógica do trabalho instável e desregulamentado. Essa massa de trabalhadores genéricos, com uma formação equivalente em diversos países, permitiria uma mobilidade ainda maior do capital, bem como uma redução de salários como produto do aumento da competição entre os trabalhadores, com tendência à desregulamentação das profissões. Sobre esse aspecto o documento da UFBA (2007a) critica frontalmente a elaboração das diretrizes curriculares pelo que chamam de "corporações profissionais", o que seria, segundo o documento, uma perda de autonomia e uma submissão dos currículos ao mercado. ${ }^{11}$

A matriz do Projeto UniNova é o Projeto Tunning, parte do Processo de Bolonha, elaborado na Europa e transplantado para a América Latina pelo Projeto Tunning - América Latina. Segundo os documentos da UFBA (2007a, p. 28):

Os princípios da Universidade Nova tomam como referência pedagógica competências desenvolvidas no Projeto Tuning - América Latina, um consórcio de 62 universidades latino-americanas, incluindo instituições brasileiras. Com essa iniciativa, procurou-se iniciar um diálogo para melhorar a colaboração entre essas instituições de educação superior, favorecendo o desenvolvimento da qualidade, da efetividade e da transparência no intuito de identificar tanto competências genéricas proporcionadas pela educação superior como competências específicas relacionadas às profissões. Esses pontos comuns identificados surgiram da necessidade de alargar os canais destinados ao reconhecimento das titulações na região e com outras regiões do planeta.

11. Argumentos infundados, em nossa opinião, que operam para minar a lógica de regulamentação das profissões. Essa regulamentação serve muitas vezes, como no caso do Serviço Social, exatamente para proteger o arcabouço profissional do pragmatismo do mercado que é beneficiado, isso sim, pela flexibilização dos currículos e a formação polivalente dos futuros trabalhadores. 
Essas competências genéricas, definidas pelo Projeto Tunning, são as mesmas que orientam os projetos pedagógicos da UniNova, bastantes adequadas às competências definidas também pela Unesco. A noção de competência substitui a de conteúdos acadêmicos e sintetiza a combinação de conhecimentos teóricos, capacidade de aplicação prática e valores (Aboites, 2009). No Tunning há 25 competências genéricas, além das competências específicas de cada carreira, estando todos no UniNova, quais sejam: responsabilidade social e compromisso cidadão, capacidade de comunicação oral e escrita, capacidade de comunicação em um segundo idioma, habilidades no uso das tecnologias da informação e da comunicação, capacidade de investigação, capacidade de aprender e atualizar-se permanentemente, capacidade de crítica e autocrítica, capacidade para atuar em novas situações, capacidade criativa, capacidade para identificar, planejar e resolver problemas, capacidade para tomar decisões, capacidade de trabalho em grupo, capacidade de motivar e conduzir para metas comuns, compromisso com a preservação do meio ambiente, compromisso com seu meio sociocultural, valorização e respeito pela diversidade e multiculturalidade, habilidade para trabalhar em contextos internacionais, habilidade para trabalhar de forma autônoma, capacidade para formular e gerir projetos, compromisso ético, compromisso com a qualidade, capacidade de abstração, análise e síntese, capacidade de aplicar os conhecimentos na prática, capacidade para organizar e planejar o uso do tempo, conhecimentos sobre uma área de estudo ou profissão.

Aboites (2009, p. 10) critica o projeto, em primeiro lugar, porque ele fere a autonomia universitária e teve um processo de definição das competências centralizador, restritivo e inclinado ao pensamento único. Do ponto de vista pedagógico-educativo, o autor define a lógica das competências como abstrata e irreal, pois desconsidera as diferenças regionais, os contextos sociais, a diversidade, a cultura e a pluralidade de visões e enfoques da realidade, gerando um ensino fragmentado que conduz ao que chama de "profissionais de manual". Cada competência é tomada em si mesma, sem relacionar-se com o todo.

A lógica de estrutura curricular propriamente dita, proposta pela UniNova, passa a dividir o ensino superior em três ciclos: o bacharelado interdisciplinar, a formação profissional em licenciaturas ou carreiras específicas e a formação em nível de pós-graduação. 
Os Bacharelados Interdisciplinares (BI) compreendem "uma nova modalidade de curso de graduação", "interdisciplinar, geral e propedêutica" (UFBA, 2007a, p. 13). Tem duração de três anos e é pré-requisito para os outros ciclos. Ao término do BI o estudante passa por uma nova seleção, para ingressar no segundo ciclo. A titulação, ao fim do BI, refere-se a uma área de concentração, sendo cada um dos quatro BIs (Artes, Humanidades, Ciência e Tecnologia e Saúde) composto por várias áreas. Os estudantes terão, ainda, a opção de fazer apenas os dois primeiros anos do BI, de formação geral, saindo com um diploma de curso sequencial, que permite acesso aos cursos tecnológicos, que fornecem diploma de tecnólogo após dois ou três semestres.

Após os Bis, os alunos poderão ingressar em cursos de licenciatura, com mais um a dois anos de formação, cursos profissionais, com mais dois a quatro anos de formação, ou diretamente para programas de pós-graduação, se aprovados em processos seletivos, para tornarem-se docentes ou pesquisadores.

A ideia dos três ciclos assemelha-se ao que vem sendo implementado pelo Processo de Bolonha, mantendo a centralidade da mobilidade estudantil, já que os alunos podem disputar nacionalmente as vagas a cada ciclo de formação. $\mathrm{Na}$ Europa, essa política tem sido criticada pelos estudantes, pois se mantém os entraves financeiros à mobilidade, que não é acompanhada de políticas compatíveis de assistência (Lima et al., 2008). Na UniNova, a assistência se traduz em políticas de cotas associadas a projetos de permanência, voltados, de forma focalizada e meritocrática, aos segmentos mais pauperizados.

Na prática, as reestruturações acadêmico-curriculares dentro do Reuni têm acontecido com diferentes ritmos e compreensões. Em janeiro de 2010, a Andifes publicou o Relatório de Acompanhamento do Programa de Apoio a Planos de Reestruturação e Expansão das Universidades Federais (Reuni). Nesse relatório são repassadas as informações enviadas pelas universidades sobre os avanços realizados nos vários aspectos do programa. No que tange às reestruturações acadêmico-curriculares, 45 das 53 universidades que aderiram ao Reuni, ou seja, $85 \%$, afirmam ter inovações em curso.

Apesar de todas as universidades estarem adequadas ao discurso, pregando flexibilização e mobilidade, os graus de mudança são distintos, refletindo inclusive as diferenças de ponto de partida.

Apenas oito universidades já implementaram ou pretendem implementar um sistema de BI, destacando-se a UFBA e a UnB, que já estão fazendo con- 
cursos de acesso para esse modelo. A UFJF, a UFT e a UFVJM implementaram BIs para alguns cursos, a UFRN implementou um BI de dois ciclos, a Ufersa apenas para as Engenharias, e a Unifesp vai implementar os BIs em 2011.

A maioria das universidades tem, até o momento, caminhado para um novo modelo por meio da criação de cursos interdisciplinares, em alguns casos dirigidos por várias unidades acadêmicas e centros setoriais. Algumas, como a UFGD e a UFLA, começaram a implementar ciclos básicos de três semestres comuns a todos os cursos.

Mas também chama atenção como dezessete universidades declaram como inovações curriculares apenas mudanças muito pontuais na estrutura dos currículos, na estrutura administrativa e na mobilidade interna dos estudantes.

Destacamos, ainda, como seis universidades consideraram inovações a introdução do EAD parcial para o ensino presencial e dois consideraram políticas de bolsas para estudantes de pós-graduação exercerem atividades de ensino, que deveriam ser ministradas por docentes, como inovações importantes.

Essas inovações, em particular, se fazem necessárias na medida em que a expansão proposta de matrículas não é proporcional ao aumento de docentes, o que traz a necessidade de "alternativas" pedagógicas. Essa é a realidade que analisaremos na próxima seção.

\section{Expansão: a ampliação para menos}

A meta global número um do Reuni é a ampliação da relação de alunos de graduação em cursos presenciais por professor para dezoito ao final de cinco anos. Segundo os Relatórios de Gestão da UFF e da UFRJ, ${ }^{12}$ elaborados pelos

12. Para ter uma melhor compreensão de como tem se dado a implementação do Reuni, tomaremos como exemplo a realidade da UFRJ e da UFF. A UFRJ é uma universidade de grande porte. Em 2007, antes do início do Reuni, contava com 141 cursos de graduação, 87 de mestrado e 73 de doutorado, totalizando 36.174 alunos de graduação e 7.650 de pós-graduação além de oito HUs e centros importantes de P\&D como a Coppe. Isso tenderia a classificá-la, na lógica do governo, como uma universidade de pesquisa (UFRJ, 2007). Já a UFF é uma universidade de médio porte, que em 2007 possuía 70 cursos de graduação presenciais, totalizando 22.943 alunos, e 43 programas de pós-graduação, totalizando 3.382 alunos. Seria caracterizada, portanto, como uma universidade de ensino (UFF, 2007). 
critérios do TCU, a relação professor/aluno era em 2007 de 1 para 10 na UFF, e 1 para 13 na UFRJ.

Portanto, para atingir essa meta, a expansão do número de docentes não pode ser proporcional à expansão do número de estudantes. Ainda que o número de concursos seja maior do que nos últimos anos, a meta do Reuni é que em 2012 o número, já insuficiente, de docentes seja proporcionalmente menor do que a situação atual.

O cálculo professor/aluno (RAP) presente no documento "Diretrizes do Reuni"é:

$$
\mathrm{RAP}=\frac{\mathrm{MAT}}{\mathrm{DDE}-\mathrm{DPG}}
$$

Nessa conta, o numerador (MAT) é a soma das vagas de ingresso anuais multiplicado pela duração mínima de integralização do curso e multiplicado por $(1+$ fator de retenção), onde o fator de retenção é determinado de acordo com cada área de conhecimento. Assim o número de matrículas na graduação não equivale aos efetivamente matriculados, mas a uma estimativa que leva centralmente em consideração o número de vagas anuais oferecidas.

O denominador é DDE - docentes com equivalência de dedicação exclusiva, que é igual a soma de professores equivalentes dividido por 1,55 , que é o índice da dedicação exclusiva. ${ }^{13}$ Da DDE subtrai-se a DPG - Dedução da Pós-Graduação, que é calculado pela soma de alunos de mestrado e doutorado multiplicado pela média de avaliação da Capes, considerando-se como mínimo uma dedução de 5\% do DDE, o que seria a média nacional.

Essa dedução tem dois problemas. Em primeiro lugar desconsidera para o cálculo da RAP, ou seja, da produtividade docente no sentido colocado pelo Reuni, os alunos da pós-graduação lato sensu. Se hoje os cursos de pós-graduação lato sensu pagos (chamados eufemisticamente nos documentos da reitoria

13. Em comparação aos critérios de equivalência do TCU há um aumento da exploração do docente já no cálculo da dedicação exclusiva. Para o TCU, um docente DE equivale a 1, o mesmo que um docente 40 h. Nos critérios do REUNI o peso do docente DE aumenta 55\% multiplicado na equivalência por 1,55. 
da UFF de autofinanciados) já são a maioria, a retirada deles da carga de trabalho considerada tende a determinar de vez sua mercantilização. Em segundo lugar, a inclusão das notas do Capes, amplamente criticadas pelo seu caráter produtivista, leva a um favorecimento de universidades com cursos de pós-graduação mais consolidados. Com isso, se firmam como universidades de pesquisa que vão manter menor o número de alunos de graduação aquelas que já têm esse perfil e como universidades de ensino de graduação aquelas que têm menos tradição na pós-graduação stricto sensu.

Pode parecer pouco, mas não é. Na comparação entre a DPG da UFRJ e da UFF, percebe-se a gritante diferença entre as universidades. Segundo os acordos de metas dessas universidades com o MEC, a dedução da UFF em 2007 era de 108,32, e da UFRJ era de 1.179,72.

Disso decorre que a ampliação das matrículas de graduação na UFF, segundo o acordado pelo Reuni, deve ser o dobro da ampliação na UFRJ. Ou seja, a lógica de ampliação do Reuni já traz, em si, uma ampliação na diversificação das Ifes separando "escolões" de formação profissional de "centros de excelência" mais voltados para a pós-graduação.

É importante considerar que esse crescimento desigual entre matrículas e concursos para docentes e técnico-administrativos não é inaugurado pelo Reuni. A ampliação da relação professor-aluno de 1 para 18 já parte de um déficit de docentes anterior. Segundo dados de Silva Júnior et al. (2010), as matrículas na graduação em universidades públicas cresceram 71\% entre 1995 e 2004 . Na região Sudeste esse aumento foi de 44\%, acompanhado de uma ampliação de docentes em dedicação exclusiva de 23 mil para 26 mil, o que significa aproximadamente $15 \%$.

Essa redução proporcional do número de docentes das universidades públicas, que tende a se ampliar, associado, ainda, ao arrocho salarial, ${ }^{14}$ tem significado uma superexploração do seu trabalho, com alterações importantes da sua natureza. O professor também passa a ser vítima da reestruturação produtiva e, assim como os demais trabalhadores intelectuais que forma, passa a ser exigido em novas competências.

14. Ainda segundo Silva Júnior et al. (2010, p. 21), o salário do professor titular doutor em regime de dedicação exclusiva das universidades federais foi reduzido, com correção inflacionária, de R\$ 10.092,96 em 1995 para $\mathrm{R} \$ 7.830,13$ em 2007, um decréscimo de aproximadamente $25 \%$. 
Uma das importantes alterações na natureza do trabalho docente transforma o professor em um empreendedor, por meio da venda de pesquisas e da prestação de serviços em parcerias público privadas, captação dos fundos setoriais, entre outros mecanismos. O trabalho dos docentes passa a ser uma alternativa para o financiamento das universidades, bem como para a complementação do seu salário, o que é estimulado pelo governo. Esse estímulo fica claro, por exemplo, nas novas propostas de regulação da dedicação exclusiva do governo Lula. A proposta apresentada em julho de 2010 flexibiliza a dedicação exclusiva ampliando as possibilidades legais de os docentes receberem de outras fontes por serviços prestados. ${ }^{15}$

A polivalência se expressa na demanda por múltiplas atividades: ensino, pesquisa — dentro do critério produtivista —, extensão — sobretudo por meio da venda de serviços - e administração. Esse último aspecto tem sido cada vez mais demandado aos docentes, que sofrem com a falta de recursos financeiros, de apoio administrativo e com a complexidade dos procedimentos e processos decisórios, tornando uma atividade que deveria ser acadêmica numa substituição de profissionais técnico-administrativos, também escassos nas instituições ${ }^{16}$ (Lemos, 2010).

A flexibilidade no trabalho se expressa na necessidade de adaptação rápida a novas modalidades de cursos (rápidos, à distância), a vários modelos de avaliação quantitativos por produção, prazos reduzidos e resultados de aplicação imediata, além da já citada busca necessária por financiamento aos seus projetos (Lemos, 2010, p. 32). Essa necessidade, por sua vez, amplia a competitividade entre professores e entre alunos, o individualismo e, consequentemente, a alienação no trabalho.

Ao mesmo tempo, o docente tem, cada vez mais, seu trabalho controlado, perdendo sua autonomia. Isso ocorre pela falta de financiamento à pesquisa, que fica subordinada a convênios e editais, à ampliação da função reguladora

15. Para aprofundar esse debate ver as análises do Andes em: $<$ http://www.andes.org.br/imprensa/ultimas/contatoview.asp?key=6720>.

16. Segundo dados do Inep citados por Silva Júnior et al. (2010), o número de funcionários técnico-administrativos decresceu em mais de 30\% nas Ifes entre 1995 e 2004. De acordo com a hipótese dos autores, as novas tecnologias permitiram uma transferência de funções dessa categoria para os docentes, que passaram a preencher planilhas de notas, programas de disciplinas e formulários de agências de fomento on-line. 
de órgãos como Sesu e o MEC, e as inúmeras avaliações internas e externas do trabalho docente e dos conteúdos programáticos, como ocorre no Enade. "Assim, a autonomia do docente vai se restringindo cada vez mais e, até, se transformando numa 'ilusão de autonomia"' (Lemos, 2010, p. 35).

O ensino, por sua vez, por ser uma atividade que não garante produtividade, novas fontes de financiamento, nem o status da pesquisa, contraditoriamente transforma-se numa atividade marginal, deixando de ser prioridade para instituições e para os próprios docentes (Lemos, 2010).

Todas essas mudanças impostas ao trabalho docente no ensino superior são a expressão da reestruturação produtiva para esse segmento da classe trabalhadora e tende a ampliar a sujeição da subjetividade docente aos interesses do capital e a alienação em relação ao seu trabalho. Associa-se isso ao refluxo do movimento sindical, também comum a outros setores da classe trabalhadora: "A reestruturação do trabalho acadêmico, o esvaziamento material e cultural da universidade pública, a diferenciação e hierarquização dos docentes, enfim, a ofensiva neoliberal impôs, na década de 90, a desmobilização e o recuo defensivo do movimento docente" (Lemos, 2010, p. 36).

Entre os docentes, Lemos (2010) demonstra variadas posições em relação à participação e à percepção do movimento sindical, que vão desde a rejeição à discussão política até a assunção de um papel político limitado ao exercício profissional, constituindo uma nova concepção de militância fora da participação de órgãos de classe ou partidos políticos.

[...] ao se afastarem da militância, buscaram construir um papel como professor, que pudesse se aproximar desse papel militante. Essa aproximação inclui a dimensão de ser um "observador crítico", "um apoiador da decisão coletiva da greve" e a "assessoria a organismos sociais, por intermédio de uma visão crítica da realidade". Por outro lado, as assembleias, congressos e encontros contam com um número cada vez mais reduzido de professores para a deliberação do movimento docente, o qual termina sendo criticado por aqueles que não comparecem às atividades políticas do movimento. (Lemos, 2010, p. 36)

Essa situação é ainda pior entre os novos professores, que, sem experiência política anterior, já ingressam nas universidades com grande condicionamento aos valores neoliberais. 
Silva Júnior et al. (2010) apontam ainda que a atividade imaterial, como a exercida pelos docentes, caracteriza-se pelo limite pouco perceptível, sobretudo quando é um trabalho superqualificado que dá prazer ao trabalhador. Esse elemento, associado ao enfraquecimento das organizações de classe e à retórica de adesão típica da reestruturação produtiva, levam a um excesso de trabalho que pode significar um aumento da incidência de doenças mentais ou somáticas na categoria. Ao mesmo tempo, a mercantilização do conhecimento faz com que toda essa sobrecarga de trabalho esteja cada vez mais a serviço do capital, e não da maioria da população, com a mediação do Estado.

Mas mesmo com toda a propaganda da expansão de vagas nas universidades federais, como vimos às custas da sobrecarga do trabalho docente, os dados do Inep demonstram que durante o governo Lula o percentual de vagas públicas em relação ao total não aumentou, pelo contrário. $O$ total de vagas no ensino superior cresceu $46 \%$ entre 2002 e 2008, sendo que as vagas nas universidades federais cresceram apenas $20,9 \%$, e o total de vagas públicas, $21,1 \%$.

\section{Contrarreforma nas universidades federais: impactos na formação dos assistentes sociais}

Nossa hipótese é que a contrarreforma, necessidade estrutural para o capitalismo tardio, é frontalmente contraditória ao projeto de formação profissional dos assistentes sociais, que compõe o projeto ético-político hegemônico. Ao contrário, adequando a formação da mão de obra intelectual a um novo modelo de produção também busca-se adequar os assistentes sociais, bem como outros profissionais ligados principalmente a instituições da superestrutura da sociedade, a uma nova forma de regulação e reprodução social, mediada por um novo perfil das políticas sociais.

Vamos analisar, então, alguns aspectos do Reuni sob a ótica da formação profissional preconizada pelo projeto ético-político dos assistentes sociais.

Em primeiro lugar, em relação às diretrizes curriculares, fica claro que se consolidada, a lógica dos Bacharelados Interdisciplinares inviabiliza sua implementação. Passando por um ciclo básico comum à área de Ciências Humanas, a direção dos conteúdos desse ciclo será objeto de disputa, numa universidade 
hoje hegemonizada pelo pensamento pós-moderno. No ciclo profissionalizante, ainda que se consiga manter certa autonomia para definição dos conteúdos, corre-se o risco de redução do tempo de formação, o que levaria a um aligeiramento do atual currículo.

No campo da pesquisa, acreditamos ter deixado claro com nossa argumentação que a tendência é de aumento da diferenciação entre as universidades, algumas centros de excelência e outras apenas reprodutoras de conhecimento e formadores de força de trabalho. $\mathrm{O}$ aumento do número de estudantes associado aos critérios cada vez mais rígidos de produtividade tendem a impossibilitar aos docentes a dedicação à pesquisas, ou mesmo uma distinção entre docentes que pesquisam e docentes que dão aulas para a graduação. Além disso, reduz-se e direciona-se cada vez mais o financiamento dessa modalidade às necessidades do capital, reduzindo a autonomia dos docentes na escolha de temáticas contra-hegemônicas, característica no Serviço Social. Com tudo isso a indissociabilidade entre ensino, pesquisa e extensão é, na prática, inviabilizada.

Pinto (2007) concorda com nossa hipótese e afirma:

A ameaça da contrarreforma na educação superior viabiliza a descaracterização propedêutica de nossa formação, dicotomiza os tempos e os conteúdos da formação porque num ciclo se conhecerá o pensamento produzido pela humanidade; noutro [...] ter-se-á o conhecimento técnico-operativo especializado; aos vocacionados para a pesquisa, o pleno conhecimento científico nas pós-graduações. Os fundamentos da contrarreforma da educação descaracterizam a concepção de intersecção teórico-investigativa-operativa que norteia o projeto de formação dos assistentes sociais brasileiros.

Outro aspecto das mudanças em curso no ensino superior tende também a modificar o mercado onde atuam os assistentes sociais, qual seja: o surgimento de novas ocupações materializadas em novos cursos de graduação. Em particular, destacam-se os novos cursos na área de gestão de políticas públicas, ${ }^{17}$ caminhando no sentido de "profissionalização" dos gestores dentro da lógica

17. Utilizando os dados da Andifes (2010), já era possível contabilizar nacionalmente, até o fim de 2009, cinco cursos de Saúde Coletiva, cinco de Gestão em Políticas Públicas, um de Gestão em Sistemas e Serviços de Saúde, além de cinco em Gestão de Cooperativas. 
gerencial propagada pela contrarreforma bresseriana do Estado (Brasil, 1995). Tomando a gestão das políticas públicas num sentido técnico, essas novas ocupações tendem a disputar com o Serviço Social, podendo diminuir nosso espaço de atuação na área da formulação e gestão das políticas sociais, sendo, certamente, um tema que necessita de estudos mais aprofundados.

\section{Considerações finais}

Com este texto, procuramos contribuir para colocar a pauta da contrarreforma universitária na ordem do dia do debate profissional, não entendida como um elemento externo limitador para a implementação das diretrizes curriculares formuladas pela Abepss, mas como parte estrutural do projeto contrarreformista colocado em curso pelo capital nas últimas décadas, que atinge em cheio o coração do projeto ético-político afirmado pelo Serviço Social brasileiro, não apenas com a ampliação do ensino privado, mas com as profundas alterações em curso no ensino superior público.

Assim como as condições de trabalho dos assistentes sociais estão indissoluvelmente relacionadas às contrarreformas em curso, também a formação profissional está indissoluvelmente relacionada e limitada pela contrarreforma nas universidades. As possibilidades de implementação das diretrizes preconizadas pela Abepss encontram nesse processo um obstáculo efetivo, sobretudo nas mais recentes propostas apresentadas pelo governo Lula, como o Reuni.

É claro, no entanto, que continuam colocadas possibilidades de reversão desse processo a partir da capacidade de mobilização da sociedade em defesa da universidade pública, gratuita e de qualidade, referenciada nos trabalhadores. É urgente, portanto, que cada vez mais os assistentes sociais e suas representações, como a Abepss e os conselhos regionais e nacional, engrossem o "coro dos descontentes" junto aos movimentos sindical e estudantil das universidades na defesa de um ensino superior realmente voltado para os interesses e as necessidades da maioria da população, na mesma direção do que é preconizado pelo projeto ético-político dos assistentes sociais brasileiros.

\section{Recebido em nov./2010 n Aprovado em abr./2011}




\section{Referências bibliográficas}

ABOITES, Hugo. La educación superior latinoamericana y el proceso de Bolonia: de la comercialización al proyecto Tuning. Conferência proferida no Seminário "Universidade, crises e alternativas”. Rio de Janeiro: Adufrj, 2009. (Mimeo.)

AMARAL, Nelson Cardoso. Financiamento da educação superior: Estado $x$ mercado. São Paulo: Cortez, 2003.

ANDES. Caderno Andes - edição revista e atualizada. Brasília, n. 2, 2003.

ANDIFES. Relatório de Acompanhamento do Programa de Apoio a Planos de Reestruturação e Expansão das Universidades Federais. Brasília: Andifes, 2010.

BANCO MUNDIAL. La enseñanza superior: las lecciones derivadas de la experiencia. Washington: The World Bank Group, 1994.

. Construir sociedades de conocimiento: nuevos desafios para la educación terciária. Washington: The World Bank Group, 2003.

BRASIL. Plano Diretor da Reforma do Estado. Brasília, 1995.

COUTINHO, Carlos Nelson. Intervenções: o marxismo na batalha das idéias. São Paulo: Cortez, 2003.

DAHMER PEREIRA, Larissa. Mercantilização do ensino superior e a formação profissional em Serviço Social: em direção a um intelectual colaboracionista? Revista Ágora, Rio de Janeiro, v. 1, 2007.

DECLARAÇÃO DE BOLONHA. Bolonha, 1999. Disponível em: <http://www.ond. vlaanderen.be/hogeronderwijs/bologna/links/language/1999_Bologna_Declaration_Portuguese.pdf $>$. Acesso em: 26 ago. 2010.

DRUCK, Graça; FILGUEIRAS, Luiz. O projeto do Banco Mundial, o governo FHC e a privatização das universidades federais. Plural, São Paulo, USP, v. 6, n. 9, p. 15-27, jan./jun. 1996.

IAMAMOTO, Marilda Vilela. O Serviço Social na contemporaneidade: trabalho e formação profissional. São Paulo: Cortez, 2003.

. Serviço Social em tempo de capital fetiche: capital financeiro, trabalho e questão social. São Paulo: Cortez, 2007.

INEP. Censo da Educação Superior 2008: dados preliminares. Brasília: MEC, 2009. 
LEHER, Roberto. Um novo Senhor da educação? A política educacional do Banco Mundial para a periferia do capitalismo. Outubro, São Paulo, n. 1, p. 19-30, 1999.

LEMOS, Denise. Alienação do trabalho docente? O professor no centro das contradições. Universidade e Sociedade, Brasília, n. 45, p. 27-37, 2010.

LIMA, Kátia Regina de Souza. Contra-reforma na educação superior: de FHC a Lula. São Paulo: Xamã, 2007.

. Universidades federais e o Reuni: alterações nas funções da universidade pública brasileira. Revista Advir, Rio de Janeiro, n. 23, p. 20-27, 2009.

LIMA, Licínio C.; AZEVEDO, Mario Luiz Neves et al. O processo de Bolonha, a avaliação da educação superior e algumas considerações sobre a Universidade Nova. Avaliação, Campinas, n. 1, p. 7-36, 2008. Disponível em: <www.scielo.com.br>. Acesso em: 3 jun. 2010.

MANDEL, Ernest. Os estudantes, os intelectuais e a luta de classes. Lisboa: Antídoto, 1979 .

. O capitalismo tardio. São Paulo: Abril Cultural, 1982.

MEC. Diretrizes do Reuni. Brasília, 2007.

NETTO, José Paulo. Transformações societárias e Serviço Social: notas para uma análise prospectiva da profissão no Brasil. Serviço Social \& Sociedade, São Paulo, n. $50,1996$.

NEVES, Lucia Maria Wanderley; PRONKO, Marcela Alejandra. O mercado do conhecimento e o conhecimento para o mercado. Rio de Janeiro: EPSJV, 2008.

PINTO, Marina Barbosa. A contra-reforma do ensino superior e a desprofissionalização da graduação em Serviço Social. Revista Ágora, Rio de Janeiro, v. 6, 2007. Disponível em: <www.assistentesocial.com.br>. Acesso em: 8 jun. 2010.

RISTOFF, Dilvo. Boyer Comission: o modelo americano em debate. In: TRINDADE, Hélgio (Org.). Universidade em ruínas na república dos professores. Petrópolis: Vozes, 1999.

SILVA JÚNIOR, João dos Reis et al. Trabalho intensificado na universidade pública brasileira. Universidade e Sociedade, Brasília. n. 45, p. 9-25, 2010.

TRINDADE, Hélgio. As metáforas da crise: da "universidade em ruínas" às "universidades na penumbra" na América Latina. In: GENTILLI, Pablo (Org.). Universidades na penumbra: neoliberalismo e reestruturação universitária. São Paulo: Cortez, 2001. 
UFBA. Plano de Expansão e Reestruturação da arquitetura curricular da UFBA: documento preliminar para consulta pública. Bahia, 2007a. Disponível em: <www. twiki.ufba.br/twiki/bin/view/UniversidadeNova/>. Acesso em: 7 jun. 2010.

. Plano de Expansão e Reestruturação da arquitetura curricular da UFBA: termo de referência. Bahia, 2007b. Disponível em: <www.twiki.ufba.br/twiki/bin/view/UniversidadeNova/>. Acesso em: 7 jun. 2010.

UFF. Relatório de Gestão 2007. Disponível em: <www.uff.br>. Acesso em: 8 jun. 2010.

UFRJ. Relatório de Gestão 2007. Disponível em: <www.ufrj.br>. Acesso em: 8 jun. 2010. 